\title{
Isolation and characterization of 19 polymorphic microsatellite loci from the topmouth gudgeon, Pseudorasbora parva
}

\author{
C. Zeng, Y. Gul, K. Yang, L. Cui, W.-M. Wang and Z.-X. Gao
}

Key Lab of Agricultural Animal Genetics, College of Fishery, Breeding and Reproduction of Ministry of Education, Huazhong Agricultural University, Wuhan, China

Corresponding author: Z.-X. Gao

E-mail: gaozexia@hotmail.com

Genet. Mol. Res. 10 (3): 1696-1700 (2011)

Received May 9, 2011

Accepted June 28, 2011

Published August 16, 2011

DOI http://dx.doi.org/10.4238/vol10-3gmr1477

\begin{abstract}
The Asiatic topmouth gudgeon, Pseudorasbora parva, is recognized as one of the most invasive fish species in many countries outside of Asia. We isolated and characterized 19 microsatellite loci from P. parva. The polymorphism of these 19 loci was tested on 40 individuals of $P$. parva sampled from a wild population located in Ezhou, Hubei province of China. The loci had 5 to 11 alleles, with a mean of 7.7 at each locus; 11 loci conformed to Hardy-Weinberg equilibrium. The expected and observed heterozygosities ranged from 0.237 to 0.973 and from 0.647 to 0.914 , respectively. All microsatellite loci were in linkage equilibrium. These microsatellite markers are
\end{abstract}


potentially useful for the assessment of population genetic structure during invasion and dispersal of P. parva in new habitats.

Key words: Pseudorasbora parva; Invasive species; Microsatellite; Polymorphism

\section{INTRODUCTION}

The Asian topmouth gudgeon (Pseudorasbora parva) is a small cyprinid that is widely distributed in the littoral zones of freshwater habitats throughout China, Japan and Korea (Okuda et al., 1996; Priyadarshana et al., 2001). Aspects of the life history of this species that predispose it to settle in new aquatic basins include a wide tolerance of environmental conditions, reaching sexual maturity in the first year of life, batch spawning and nest guarding (Sunardi et al., 2005; Prinder et al., 2005; Kapusta et al., 2008).

By the end of the 2000s, in slightly over 40 years, $P$. parva has colonized almost all of Europe, proceeding rapidly from east to west (Witkowski, 2011). Most probably it was introduced in European countries with stocking material of herbivorous fishes that were imported from China for several decades, and is now considered to be an effective invasive species in Europe (Bianco, 1988). It not only feeds on juvenile stages of many valuable native fish species, but also competes for food with farmed fish species (Sunardi et al., 2005; Žitnan and Holčik, 1976). Most importantly it consumes larger species of planktonic crustaceans, which results in an increase in the quantity of phytoplankton, and further increases eutrophication of water bodies (Gozlan et al., 2005). Besides, being a vector of infectious diseases (Spherotecum destruens, among others), it constitutes a serious threat to both native and farmed fishes in Europe (Britton et al., 2010). Most studies on P. parva have focused on invasion, behavior and toxicology, while the details of their genetic characteristics have been rarely reported. In the current study, we have isolated and characterized a batch of novel polymorphic microsatellites from the genome of $P$. parva, which are potentially helpful in the study of its population genetic structure during invasion and fast dispersal after invasion.

\section{MATERIAL AND METHODS}

DNA used for microsatellite-enriched libraries was extracted by traditional proteinase-K digestion and phenol-chloroform protocol with RNase treatment from caudal fin of P. parva. Approximately $200 \mathrm{ng}$ extracted DNA was completely digested using the restriction enzyme HaeIII (BioLabs) and then ligated to adapters (5'-CTC TTG CTT GAA TTC GGA CTA-3'/5'-TAG TCC GAA TTC AAG CAA GAG CAC A-3') by T4 DNA ligase (BioLabs) in a $20-\mu \mathrm{L}$ volume at $16^{\circ} \mathrm{C}$ for $10 \mathrm{~h}$. The digestion-ligation mixture was diluted (1:10) and directly amplified using an adapter-specific primer (5'-CTC TTG CTT GAA TTC GGA CTA-3'). The polymerase chain reaction (PCR) amplification program was conducted as follows in a $20-\mu \mathrm{L}$ volume: a predenaturation at $94^{\circ} \mathrm{C}$ for $10 \mathrm{~min} ; 30$ cycles including denaturation at $94^{\circ} \mathrm{C}$ for $30 \mathrm{~s}$, annealing at $52^{\circ} \mathrm{C}$ for $30 \mathrm{~s}$ and elongation at $72^{\circ} \mathrm{C}$ for $45 \mathrm{~s}$, and a final extension at $7^{\circ} \mathrm{C}$ for $10 \mathrm{~min}$. The PCR products were hybridized with 400 pmol of 5'-biotinylated $(\mathrm{AC})_{8}$ or $(\mathrm{CT})_{8}$ oligonucleotide probe, by denaturing DNA for $10 \mathrm{~min}$ at $95^{\circ} \mathrm{C}$, and then incubated at $55^{\circ} \mathrm{C}$ for $30 \mathrm{~min}$. 
The hybridized DNA fragments were enriched by Streptavidin MagneSphere Paramagnetic Particles (Promega). The fragments were amplified for 30 cycles with an adapter-specific primer and the same program mentioned above was used. The amplified DNA fragments were isolated and purified by AxyPreDNAGel Extraction Kit (AXYGEN). Then, the purified DNA fragments were ligated into the $\mathrm{pMD}^{\mathrm{TM}} 18-\mathrm{T}$ vector (TaKaRa) and transformed into competent Escherichia coli DH5 $\alpha$ cells. Grown overnight on LB solid medium with ampicillin, 221 positive clones were picked up and confirmed by PCR.

After PCR confirmation, 29 positive clones were sequenced and contained simple sequence repeats. Sequences were analyzed for the repeat region using the Tandem Repeats Finder software (Benson, 1999). The PRIMER 3 software (Rozen and Skaletsky, 2000) was then used to design 29 pairs of primers flanking the repeat regions of interest. PCR conditions were optimized for each pair of primers with a gradient PCR at $40-60^{\circ} \mathrm{C}$ range of annealing temperatures. Each reaction contained about $20 \mathrm{ng}$ DNA, $2.0 \mathrm{mM}$ $\mathrm{MgCl}_{2}, 0.4 \mathrm{mM}$ dNTPs, $0.5 \mu \mathrm{M}$ each primer, $1 \mathrm{X}$ Taq buffer, and $0.5 \mathrm{U}$ Taq polymerase (Fermentas). PCR was conducted with the following programs: initial denaturation at $94^{\circ} \mathrm{C}$ for $10 \mathrm{~min} ; 30$ cycles at $94^{\circ} \mathrm{C}$ for $30 \mathrm{~s}$, annealing at a locus-specific temperature (Table 1) for $30 \mathrm{~s}$, elongation at $72^{\circ} \mathrm{C}$ for $45 \mathrm{~s}$, and a final extension at $72^{\circ} \mathrm{C}$ for $10 \mathrm{~min}$.

The polymorphism test was performed on 40 individuals of $P$. parva sampled from a wild population located in Ezhou, Hubei province of China. Electrophoresis for the amplified products was conducted on $8 \%$ nondenaturation polyacrylamide gel and visualized by silver staining. Alleles were identified by pUC18/mspI (TIANGEN). The number of alleles, the observed heterozygosity $\left(H_{O}\right)$, the expected heterozygosity $\left(H_{E}\right)$, Hardy-Weinberg equilibrium $(H W E)$, and pairwise tests for linkage disequilibrium were performed using the POPGENE 32 computer program. Significance criteria were adjusted for the number of simultaneous tests using Bonferroni's correction.

\section{RESULTS AND DISCUSSION}

In total, among the 29 microsatellite primers, 19 primer pairs produced polymorphic DNA products, 10 primer pairs were amplified without any result. The number of alleles at the 19 polymorphic microsatellite loci ranged from 5 to 11 with a mean of 7.7. $H_{E}$ and $H_{O}$ ranged from 0.237 to 0.973 and from 0.647 to 0.914 , with an average of 0.758 and 0.792 , respectively (Table 1). Significant deviations from Hardy-Weinberg equilibrium were observed in 11 loci $(P>0.05)$ as shown in Table 1. No significant linkage disequilibrium was detected between any pair of loci.

Nineteen microsatellites isolated in the present study were highly polymorphic, and they could potentially be useful for further studies of population genetics. They could provide clues to assess the genetic diversity and genetic structure of invasive populations of $P$. parva, and serve to reveal changes through space and time in comparison to native populations, which could lead to the identification of general features of the invasive process of this species.

\section{ACKNOWLEDGMENTS}

Research supported by the National Water Environmental Monitoring Technology System Research and demonstration titled as - R\&D, Application and Demonstration of New Technique and Protocol in Water Environmental Monitoring (\#2009ZX07527-005). 


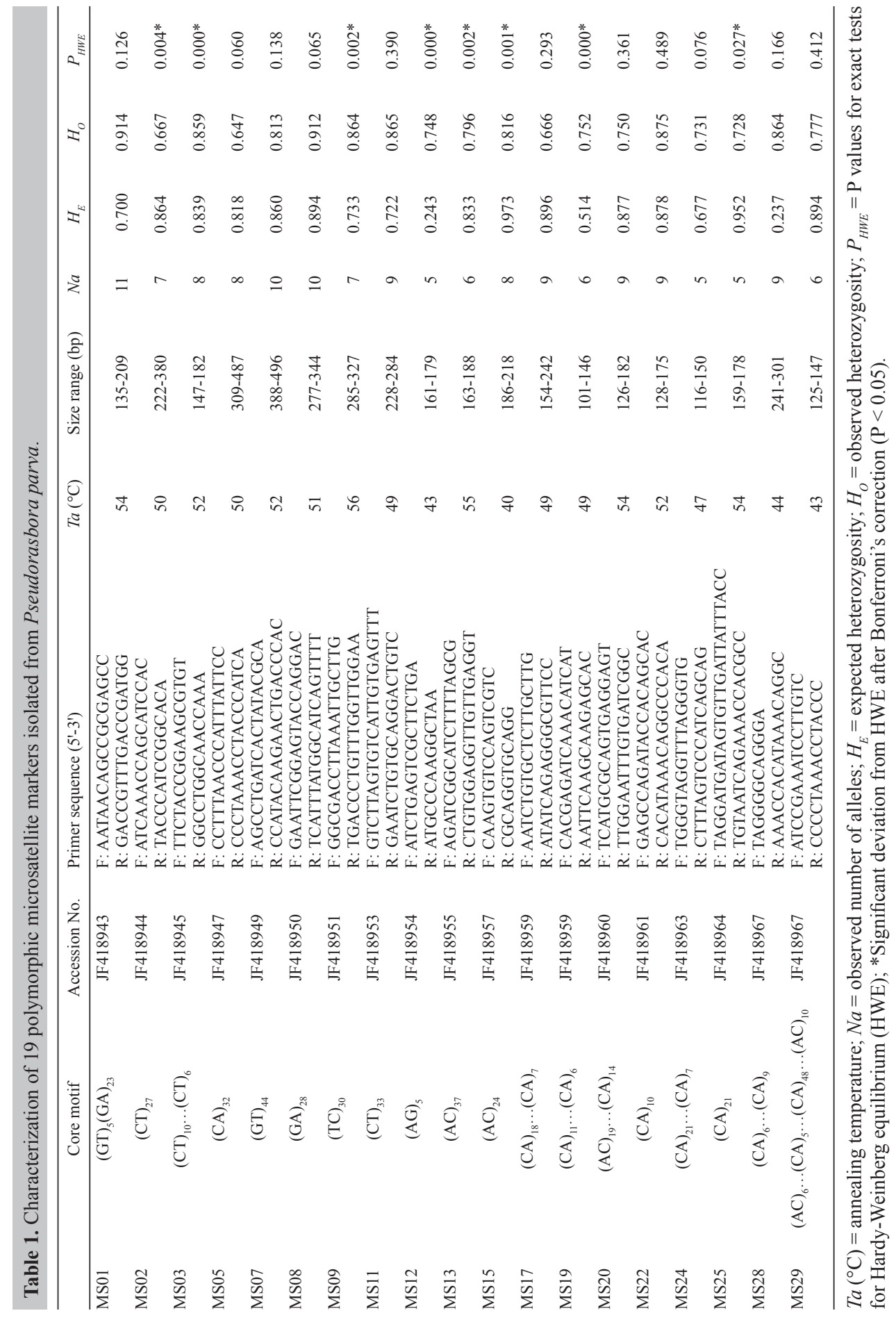




\section{REFERENCES}

Benson G (1999). Tandem repeats finder: a program to analyze DNA sequences. Nucleic Acids Res. 27: 573-580.

Bianco PG (1988). Occurrence of the Asiatic gobionid Pseudorasbora parva (Temminck and Schlegel) in south-eastern Europe. J. Fish. Biol. 32: 973-974.

Britton JR, Davies GD and Brazier M (2010). Towards the successful control of the invasive Pseudorasbora parva in the UK. Biol. Invasions 12: 125-131.

Gozlan RE, St-Hilaire S, Feist SW, Martin P, et al. (2005). Biodiversity: disease threats to European fish. Nature 435: 1046.

Kapusta A, Bogacka-Kapusta E and Czarnnecki B (2008). The significance of stone moroko, Pseudorasbora parva (Temminck and Schlegel), in the small-sized fish assemblages in the littoral zone. Arch. Pol. Fish. 16: 49-62.

Okuda S, Shibata T, Shimatani Y and Mizuno N (1996). Cyclopedia of River Biota. Prepared for Japanese River Front Planning and Management Centre. Sankaido Publishers, Tokyo.

Prinder AC, Gozlan RE and Britton JR (2005). Dispersal of the invasive topmouth gudgeon, Pseudorasbora parva in the UK: a vector for an emergent infectious disease. Fish. Manag. Ecol. 12: 411-414.

Priyadarshana T, Asaeda T, Manatunge J and Tanaka N (2001). Characteristics of foraging behaviour of Pseudorasbora parva in habitats of artificial vegetation. Proc. Jpn. Soc. Civil Eng. 670: 73-82.

Rozen S and Skaletsky H (2000). Primer3 on the WWW for general users and for biologist programmers. Methods Mol. Biol. 132: 365-386.

Sunardi, Asaeda T and Manatunge J (2005). Foraging of a small planktivore (Pseudorasbora parva: Cyprinidae) and its behavioral flexibility in an artificial stream. Hydrobiology 549: 155-166.

Witkowski A (2011). NOBANIS - Invasive Alien Species Fact Sheet - Pseudorasbora parva - From: Online Database of the North European and Baltic Network on Invasive Alien Species. Available at [www.nobanis.org]. Accessed April 28, 2011.

Žitnan R and Holčik J (1976). On the first find of Pseudorasbora parva in Czechoslovakia. Zool. Listy 25: 91-95. 